\title{
Peptide-Loaded Solid Lipid Nanoparticles Prepared through Coacervation Technique
}

\author{
Marina Gallarate, Luigi Battaglia, E. Peira, and Michele Trotta \\ Dipartimento di Scienza e Tecnologia del Farmaco, via P. Giuria 9, 10125 Torino, Italy \\ Correspondence should be addressed to Marina Gallarate, marina.gallarate@unito.it \\ Received 29 July 2010; Accepted 11 January 2011 \\ Academic Editor: Cordelia Selomulya
}

Copyright ( $) 2011$ Marina Gallarate et al. This is an open access article distributed under the Creative Commons Attribution License, which permits unrestricted use, distribution, and reproduction in any medium, provided the original work is properly cited.

\begin{abstract}
Stearic acid solid lipid nanoparticles were prepared according to a new technique, called coacervation. The main goal of this experimental work was the entrapment of peptide drugs into SLN, which is a difficult task, since their chemical characteristics (molecular weight, hydrophilicity, and stability) hamper peptide-containing formulations. Insulin and leuprolide, chosen as model peptide drugs, were encapsulated within nanoparticles after hydrophobic ion pairing with anionic surfactants. Peptide integrity was maintained after encapsulation, and nanoparticles can act in vitro as a sustained release system for peptide.
\end{abstract}

\section{Introduction}

The development of colloidal carrier systems in drug administration has attracted increasing attention during recent years as innovative strategy to overcome frequent therapy failures due to unpredictable bioavailability of drugs when administered by the conventional routes and in the conventional dosage forms. The most investigated systems are simple and multiple emulsions, liposomes, micelles, microand nanoparticles based on synthetic polymers or natural macromolecules [1].

Particularly, peptides and protein drugs represent a very important class of therapeutic agents, owing to the understanding of their role in physiology and pathology as well as to the advances in biotechnology and genetic engineering. Unfortunately, they are characterised by a short biological half-life, being easily degraded by proteolytic enzymes; moreover, most peptides poorly cross biological barriers due to their poor diffusivity and low partition coefficient.

The entrapment of peptides and proteins into nanoparticulate systems still remains a difficult task, since each molecule is characterised by essential properties (e.g., molecular weight, hydrophilicity, and stability) that might be somehow different with respect to another one. This situation often hampers peptide-containing formulations, because each peptide becomes the subject of a case study. The choice of a correct formulation strategy is mainly driven by solubility and molecular stability considerations [2].

In the last twenty years, solid lipid nanoparticles (SLNs) have attracted increasing attention as efficient colloidal drug carriers, alternative to polymeric nanoparticles, with the advantage of being prepared with physiological and nontoxic lipids, used as common pharmaceutical excipients [3].

The use of lipids as matrix materials for sustained-release formulations for peptides and proteins has been reported only by a few authors $[4,5]$, owing to the hydrophobic nature of lipid matrix that can be more appropriate to incorporate lipophilic drugs rather than hydrophilic proteins.

A method to produce solid lipid nanoparticles (SLNs) from $\mathrm{W}_{1} / \mathrm{O} / \mathrm{W}_{2}$ multiple emulsions was developed by our research group applying the solvent-in-water emulsiondiffusion technique [6]. Insulin was chosen as hydrophilic peptide drug to be dissolved in the acidic inner aqueous phase $\left(\mathrm{W}_{1}\right)$ of multiple emulsions and to be consequently carried in SLN. Several partially water-miscible solvents with low toxicity were screened in order to optimise emulsions and SLN composition, after assessing that insulin did not undergo any chemical modification in the presence of the different solvents and under the production process conditions. However, it is well documented that most peptides 
might be altered to some extent by interfaces and agitation stress with this method [7].

Moreover, low-water soluble peptides (e.g., having an isoelectric point close to neutral $\mathrm{pH}$ ) should rather be dissolved in a nonaqueous solvent or suspended in an appropriate medium. In a previous work, our research group developed a technique that, applying the solvent dilution method to an $\mathrm{O} / \mathrm{W}$ emulsion with isovaleric acid as inner phase, allows to encapsulate insulin in SLN, thanks to the solubilization of insulin in isovaleric acid [8].

Another strategy to promote peptide drug encapsulation in a lipid-based particulate system is to enhance its lipophilicity by forming a drug-surfactant complex by means of an ion-pairing technique [9]. Based on the interaction of an anionic amphiphilic molecule and a positively charged protein, ion pairing takes place at surfactant concentrations below the critical micelle concentration (CMC) and at a $\mathrm{pH}$ below the isoelectric point of the protein $[10,11]$.

Recently, a new, solvent-free SLN production technique was developed by our research group [12]. Briefly, when the $\mathrm{pH}$ of a fatty acid alkaline salt micellar solution in the presence of an appropriate polymeric stabiliser, is lowered by acidification, the fatty acid precipitates owing to proton exchange between the acid solution and the soap; this process was defined as "coacervation."

This innovative technique allows to load lipophilic drugs by dissolution in the micellar solution before acidification [13] and can also be applied successfully to hydrophobic ion pairs of hydrophilic drugs [14].

The main goal of this study was to evaluate the possible use of hydrophobic ion pairing (HIP) to encapsulate insulin and leuprolide as model peptides within SLN obtained by coacervation, with respect to nanoparticle size and final drug encapsulation efficiency and release.

\section{Materials and Methods}

2.1. Materials. Lactic acid and citric acid were from A.C.E.F. (Fiorenzuola d'Arda, Italy); 80\% hydrolysed polyvinyl alcohol 9000-10000 MW (PVA9000), 89\% hydrolysed polyvinyl alcohol 85000-120000 MW (PVA85000), dextran 60000-90000, and bovine insulin $\left(M_{w}=5807\right)$ were from Sigma (Dorset, UK); sodium stearate (SS) and sodium dodecylsulfate (SDS) were from Fluka (Buchs, Switzerland); 2,3-epoxypropyl phenyl ether was from Aldrich (St Louis, USA); dioctyl sulfosuccinate (AOT) was from Merck (Darmstadt, Germany); leuprolide acetate $\left(M_{w}=1210\right)$ was a kind gift from Sorin Spa (Saluggia, Italy). Distilled water was purified using a Milli-Q system (Millipore, Bedford, $\mathrm{MO})$. All other chemicals were of analytical grade and used without further purification.

2.2. Preparation of Peptide Drugs Ion Pairs. Hydrophobic peptides ion pairs were prepared according to literature methods $[15,16]$. Acid or neutral peptide solutions were mixed with counterion solutions at various peptide: counterion molar ratios.
Insulin $(1 \mathrm{mg} / \mathrm{mL})$ was dissolved in an aqueous $\mathrm{pH} 2.5$ $\mathrm{HCl}$ solution, and an aqueous SDS solution was added at $1: 6$ molar ratio, according to literature reports [15].

Leuprolide acetate $(1 \mathrm{mg} / \mathrm{mL})$ was dissolved:

(a) in water (resulting $\mathrm{pH} 6.5$ );

(b) in an aqueous $\mathrm{pH} 4.0$ acetic acid solution;

and an aqueous AOT solution at the same $\mathrm{pH}$ values was added at $1: 1$ and $1: 2$ peptide : counterion molar ratios [16].

Both precipitates formed were centrifuged at $55000 \mathrm{~g}$ (Allegra R64 centrifuge, Beckmann Coulter), washed three times with deionised water, and then freeze-dried for $24 \mathrm{~h}$.

A weighted amount of the freeze dried product was dissolved in methanol, added of an equal volume of water, and then analysed by HPLC for peptide determination to assess the actual peptide : counterion molar ratio.

2.3. Insulin HPLC Analysis. Insulin and A21-desamido insulin, the main degradation product of insulin [17], were analysed through RP-HPLC; A21-desamido insulin was prepared by storing bovine insulin in $0.01 \mathrm{M} \mathrm{HC1}$ at $50^{\circ} \mathrm{C}$ for $48 \mathrm{~h}$ [18]. The chromatograph was equipped with a Shimadzu HPLC system (Shimadzu, Milano, Italy), set at $220 \mathrm{~nm}$. For the RP-HPLC, a C18 column (Beckman Ultrasphere $25 \times 0.4 \mathrm{~cm}$ ) was employed. The mobile phase was $0.1 \mathrm{M} \mathrm{Na} \mathrm{Na}_{4} / \mathrm{CH}_{3} \mathrm{CN}(72 / 28)$ brought to $\mathrm{pH} 2.3$ with $\mathrm{H}_{3} \mathrm{PO}_{4}$, and it was delivered at $1 \mathrm{~mL} \mathrm{~min}^{-1}$ [19]. The retention times were $11 \mathrm{~min}$ and $12.5 \mathrm{~min}$ for insulin and A21-desamido insulin, respectively. A calibration graph was constructed in the $0.8-20 \mathrm{mmol} \mathrm{L}^{-1}$ range.

The linearity of the calibration graph was demonstrated by the value $(0.9981)$ of $R^{2}$ coefficient of the regression equation: $y=6.97 \cdot 10^{10} \times-16176$. The LOQ, defined in the presented experiment as the lowest insulin concentration in the curve that can be measured routinely with acceptable precision and accuracy, was $1.0 \mathrm{mmol} \mathrm{mL}^{-1}$; the LOD, defined as the lower detection limit, was $0.40 \mathrm{mmol} \mathrm{L}^{-1}$.

2.4. Leuprolide HPLC Analysis. The chromatograph was equipped with a Shimadzu HPLC system (Shimadzu, Milano, Italy), set at $278 \mathrm{~nm}$. For the RP-HPLC, a C18 column (Chromosystem $15 \times 0.4 \mathrm{~cm}$ ) was employed. The mobile phase was $\mathrm{CH}_{3} \mathrm{OH} / \mathrm{H}_{2} \mathrm{O}(60 / 40)$ TFA $0.1 \%$, and it was delivered at $1 \mathrm{~mL} \mathrm{~min}^{-1}$. The retention time was $6 \mathrm{~min}$. A calibration graph was constructed in the $0.02-0.2 \mathrm{mmol} \mathrm{L}^{-1}$ range.

The linearity of the calibration graph was demonstrated by the value $(0.9996)$ of $R^{2}$ coefficient of the regression equation: $y=0.041 \times-0.0166$. The LOQ, defined in the presented experiment as the lowest leuprolide concentration in the curve that can be measured routinely with acceptable precision and accuracy, was $0.02 \mathrm{mmol} \mathrm{mL}^{-1}$; the LOD, defined as the lower detection limit, was $0.05 \mathrm{mmol} \mathrm{L}^{-1}$.

2.5. SLN Preparation. Stearic acid (SA) SLNs were prepared according to the coacervation method described in a previous paper [12]. Briefly, SS was dispersed in an aqueous solution of the polymeric stabiliser, and the mixture was 
then heated under stirring ( $300 \mathrm{rpm})$ up to $50^{\circ} \mathrm{C}$ to obtain a clear solution. A known amount of peptide ethanol solution $(25 \mathrm{mg} / \mathrm{mL})$ was then added and kept under stirring until complete dissolution. A selected acidifying solution (coacervating solution) was then added dropwise as described in a previous paper [12]. The obtained suspension was then cooled in a water bath under stirring at $300 \mathrm{rpm}$ until $15^{\circ} \mathrm{C}$ was reached.

2.6. SLN Characterisation. SLN particle size and size distribution were determined by the laser light scattering technique LLS (Brookhaven, New York, USA). The dispersions were diluted with water and measurements were done at an angle of $90^{\circ}$.

Drug encapsulation efficiency (EE\%) was calculated as the ratio between the amount of drug encapsulated within the lipid matrix and the amount of drug used to prepare nanoparticles. For the determination of the encapsulated drug, a known amount of SLN suspension was centrifuged at $55000 \mathrm{~g}$; the precipitate was washed either with $0.1 \mathrm{~N} \mathrm{HCl}$ or with water, for insulin and leuprolide, respectively. The precipitate was then dried and dissolved in methanol; 0.1 $\mathrm{HCl}$ or water were added to dissolve insulin and leuprolide, respectively, and to precipitate the lipid, then both peptides were analysed by HPLC.

2.7. In Vitro Leuprolide Release from Nanoparticles. A first series of experiments was performed by using the "test tube" method [20].

$10 \mathrm{~mL}$ decanol, used as organic phase, were layered onto the surface of $10 \mathrm{~mL}$ leuprolide-AOT-loaded SLN, and the system was kept under mild stirring ( $50 \mathrm{rpm})$; at scheduled times, a small amount of the receiving phase was withdrawn and the supernatant analysed spectrophotometrically at 278 for leuprolide determination.

Systems under study:

(i) $0.05 \%$ leuprolide AOT 1:2 ion pair loaded 1\% SA SLN stabilised with $0.5 \%$ PVA9000 or PVA85000;

(ii) $0.05 \%$ leuprolide AOT $1: 2$ ion pair aqueous solution as blank solution.

A second series of experiments was performed by using the model of the "diffusion through hydrophilic membrane" [21]. Release studies were done by using multicompartment rotating cells ( $1 \mathrm{~mL}$ donor and acceptor compartments) with a Servapor cellulose membrane (MWCO 12000-14000 Da, Serva, Heidelberg, Germany). Distilled water was used as receiving phase. At scheduled times, the receiving solution was withdrawn, analysed spectrophometrically at $278 \mathrm{~nm}$, and replaced with fresh receiving phase.

Systems under study:

(i) $0.05 \%$ leuprolide AOT-loaded 1\% SA SLN stabilised with $0.5 \%$ PVA85000;

(ii) $0.05 \%$ leuprolide AOT 1:2 ion pair aqueous solution as blank solution;

(iii) $0.05 \%$ leuprolide aqueous solution as blank solution.

\section{Results and Discussion}

Ion pairing between insulin and SDS is reported in literature [15]. Surfactant: peptide 1:6 molar ratio complex has been extensively studied as to chemical stability; it is noteworthy that circular dichroism spectra in far UV did not show any alteration in peptide secondary structure after ion pairing. Moreover, an enhanced resistance to high temperatures was acquired by the peptide after ion pairing [15]. These data provided a good basis for insulin encapsulation attempts within SLN. In the present work-mild operative temperatures, as well as the increased thermal resistance of insulin: SDS ion pair, were considered as good assumptions to maintain drug stability after nanoparticles preparation.

Leuprolide acetate is a synthetic nonapeptide analog of naturally occurring gonadotropin-releasing hormone ( $\mathrm{GnRH}$ or LH-RH); the analog possesses greater potency than the natural hormone. It acts as a potent inhibitor of gonadotropin secretion when given continuously and in therapeutic doses. Animal and human studies indicate that following an initial stimulation of gonadotropins, chronic administration of leuprolide acetate results in suppression of ovarian and testicular steroidogenesis. This effect is reversible upon discontinuation of drug therapy. Administration of leuprolide acetate has resulted in inhibition of the growth of certain hormone-dependent tumors (prostatic tumors in Noble and Dunning male rats and DMBA-induced mammary tumors in female rats) as well as atrophy of the reproductive organs [22]. Leuprolide has two ionisable basic side chains, one imidazole group of His $\left(\mathrm{p} K_{\mathrm{a}}=6.0\right)$ and one guanidine group of $\operatorname{Arg}\left(\mathrm{p} K_{\mathrm{a}}=13.0\right)$. Thus, hydrophobic ion pairing of leuprolide with various acidic amphipathic molecules such as a series of alkyl sulfonates with different hydrocarbon chain was attempted to enhance its lipophilic partition coefficient [16]. In the present experimental study, linear alkyl sulfonates were replaced by the more lipophilic AOT, which is a branched alkyl sulfonate.

The stoichiometry of the peptide counterion in the ion pair was confirmed through HPLC analysis, both for leuprolide AOT and insulin SDS. According to literature data, it was noticed that in deionised water (neutral $\mathrm{pH}$ ) a $1: 1$ leuprolide monoacetate: AOT ion pair was formed. At pH 4.0 (acetic acid) leuprolide diacetate was present and a $1: 2$ ion pair was obtained. Changes in ion pair stoichiometry are dependent on $\mathrm{pH}$, but not on AOT concentration, since no further change in stoichiometry was noted by increasing drug: counterion molar ratio up to $1: 4$, neither at neutral $\mathrm{pH}$, nor at $\mathrm{pH} 4.0$.

In Table 1 composition, mean size and encapsulation efficiency (EE\%) of blank and peptide-loaded SLN are shown.

As it can be noted, several leuprolide-loaded, 1\% SA SLN stabilised with different concentrations of two different polymers were prepared. Leuprolide-loaded 1\% SLN were prepared using both $1: 1$ and $1: 2$ ion pairs. In order to improve EE\% of 1:1 ion pair, PVA9000 concentration was reduced from $1 \%$ to $0.25 \%$, since high concentrations of the polymer can enhance ion pair solubility in the outer phase. With decreasing polymer concentration, an increase in mean particle size was noted without enhancing EE\%, probably 
TABLE 1: SLN composition, mean diameter, and EE\%.

\begin{tabular}{|c|c|c|c|c|c|c|c|}
\hline & \multicolumn{4}{|c|}{ 1:1 Leuprolide AOT } & \multicolumn{2}{|c|}{$1: 2$ Leuprolide AOT } & \multirow{2}{*}{$\begin{array}{c}\text { Insulin-loaded } \\
2 \% \mathrm{SLN}\end{array}$} \\
\hline & & loade & 0 SLN & & loades & & \\
\hline & $1 \%$ & $0.25 \%$ & $0.5 \%$ & $0.5 \%$ & $0.5 \%$ & $0.5 \%$ & $2 \%$ \\
\hline & PVA9000 & PVA9000 & PVA9000 & PVA85000 & PVA9000 & PVA85000 & PVA9000 \\
\hline SS (mg) & $107^{*}$ & $107^{*}$ & $107^{*}$ & $107^{*}$ & $107^{*}$ & $107^{*}$ & $215^{* *}$ \\
\hline PVA9000 (mg) & 100 & 25 & 50 & & 50 & & 200 \\
\hline PVA120000 (mg) & & & & 50 & & 50 & \\
\hline Leuprolide (mg) & 5 & 5 & 5 & 5 & 5 & 5 & \\
\hline Insulin (mg) & & & & & & & 5 \\
\hline AOT (mg) & 1.55 & 1.55 & 1.55 & 1.55 & 3.1 & 3.1 & \\
\hline SDS (mg) & & & & & & & 1.5 \\
\hline $1 \mathrm{M}$ lactic acid (mL) & 0.5 & 0.5 & 0.5 & 0.5 & 0.5 & 0.5 & 1 \\
\hline Water (mL) & 9.5 & 9.5 & 9.5 & 9.5 & 9.5 & 9.5 & 9.0 \\
\hline Mean size (nm) & $320 \pm 30$ & $522 \pm 45$ & $377 \pm 36$ & $338 \pm 29$ & $390 \pm 45$ & $350 \pm 30$ & $418 \pm 39$ \\
\hline polydispersity & 0.050 & 0.260 & 0.224 & 0.048 & 0.201 & 0.060 & 0.055 \\
\hline EE\% & $48.5 \pm 1.0$ & $50.4 \pm 2.1$ & $52.6 \pm 2.6$ & $53.9 \pm 1.2$ & $80.4 \pm 2.5$ & $86.8 \pm 4.0$ & $89.0 \pm 2.0$ \\
\hline
\end{tabular}

* corresponding to $100 \mathrm{mg} \mathrm{SA}$.

** corresponding to $200 \mathrm{mg} \mathrm{SA}$.

because PVA9000 acts as a steric stabiliser, which covers SLN surface thus avoiding nanoparticles aggregation; by decreasing polymer concentration, nanoparticles mean size will increase probably because of aggregation phenomena. The use of a higher-molecular-weight PVA (85000 instead of 9000) did not affect EE\%, which remained nearly 50\%. A significant increase in EE\% (up to 86.8) was reached when 1:2 leuprolide:AOT ion pair was loaded in SLN, which was quite independent of the polymer used. Probably, the higher lipophilicity of $1: 2$ ion pair in respect to $1: 1$ one determines a better drug allocation in the hydrophobic core of SS micelles and consequently, in SA-SLN. Polymer-ion pair interactions seemed not to be relevant in leuprolide $\mathrm{EE} \%$.

Otherwise, in the case of insulin-loaded SLN, 2\% of both lipid and polymer (PVA9000) was used, since at lower concentrations of lipid and PVA9000, nanoparticles aggregation occurred, probably because of a perturbation of SS micelles exerted by the high-molecular-weight peptide, during the coacervation process. The use of higher concentrations of soap and polymer probably minimises the destabilising effect of peptide encapsulation.

The effectiveness of insulin encapsulation was assessed by washing the centrifuged SLN with $0.1 \mathrm{M}$ hydrochloric acid to remove from SLN surface any adsorbed drug; a high EE\% (89\%) was revealed. Since the stability is an important issue of nanoparticles-loaded peptide, the absence of A21-desamido insulin, the commonest thermal degradation product of insulin, in SLN was assessed through RP-HPLC analysis; less than 5\% A21-desamido insulin was recovered in encapsulated drug, demonstrating the chemical integrity of peptide after the coacervation process.

To verify the effective encapsulation of ion pair within nanoparticles, drug release was studied since the encapsulation of ion pair in the solid lipid matrix, with subsequent

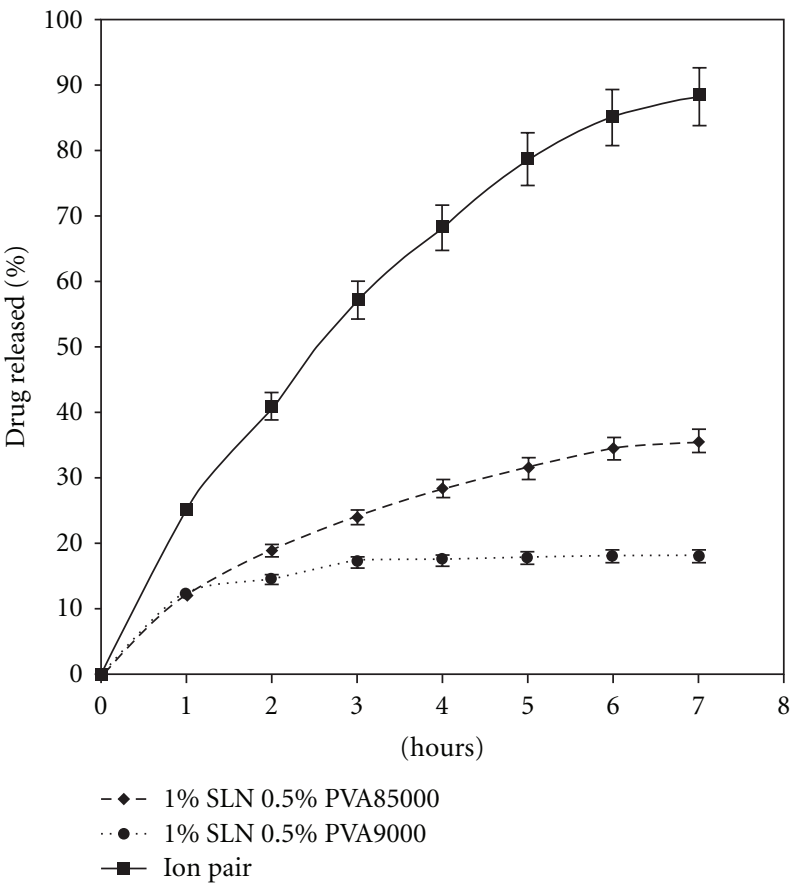

FIGURE 1: leuprolide release from SLN: test tube method.

immobilisation, causes a reduction of its release velocity [23]. Moreover, peptide release from nanoparticles is an important goal especially when prolonged and gradual delivery is needed, that is, for leuprolide in prostate cancer treatment; so leuprolide in vitro release from SLN was studied according to two different methods described in literature.

First, test tube assay was used. This method involves two steps: the release of the drug from the nanoparticles to the 


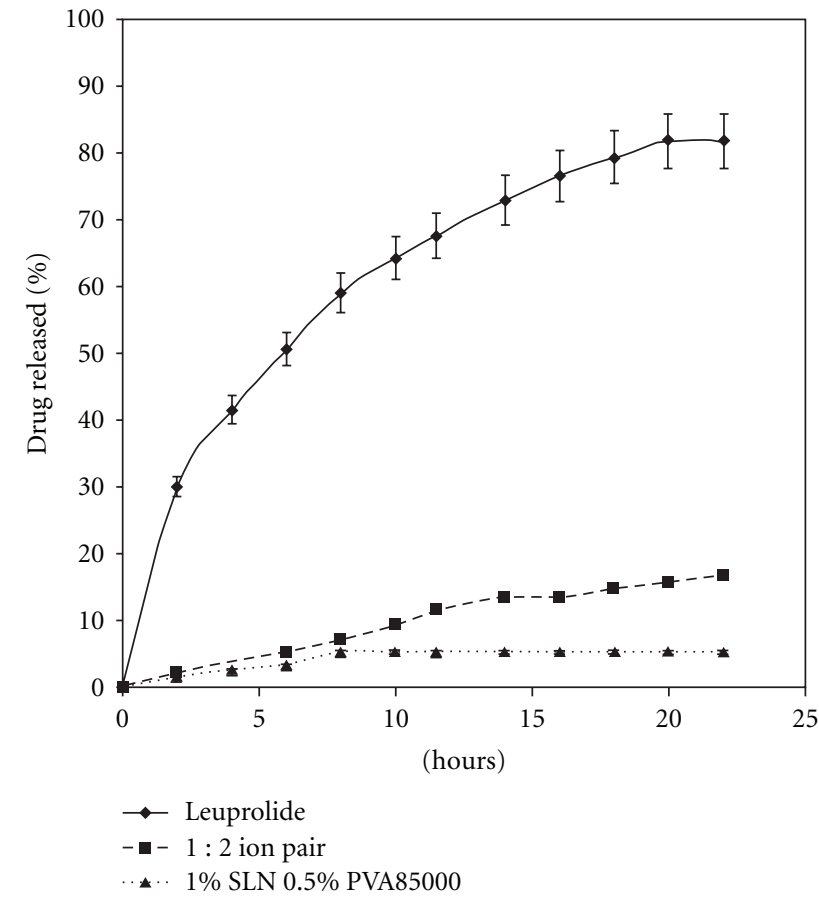

FIGURE 2: leuprolide release from SLN: method of diffusion through hydrophilic membrane.

aqueous outer phase and the migration to the organic phase, where it favourably partitions, due to the lipophilicity of the ion pair. Despite the partition step in a nonphysiological medium, this assay is suitable to obtain complete release in a few hours, since the organic phase can dissolve easily a lipophilic molecule or complex. The obtained results are shown in Figure 1. Loading the $1: 2$ ion pair in SLN caused a decrease of its release rate compared to $1: 2$ ion pair aqueous suspension, because of ion pair immobilisation within the lipid matrix. The grade of the polymer, which covers the surface of SLN acting as a steric stabiliser, might influence the release of the drug from the lipid matrix in a low extent, probably owing to its interaction with the drug adsorbed onto SLN surface.

In Figure 2, the results of diffusion studies through hydrophilic membrane are reported. This assay involves two steps, too: the crossing of the membrane and release to the receiving phase. Cellulose membrane is almost completely permeable to leuprolide within the 24 hours, so that the release to the receiving phase is the limiting step. Release of $1: 2$ ion pair decreased when it was loaded in nanoparticles, confirming the encapsulation within the lipid matrix; the release is much slower, compared to the test tube assay because of the reduced solubility of the ion pair in water compared to decanol.

\section{Conclusion}

Hydrophobic ion pairing of leuprolide and insulin, chosen as model peptides, allowed the encapsulation of these molecules in SLN produced through the coacervation technique; the stoichiometry of the ion pair is determinant for encapsulation efficiency, as demonstrated for leuprolide. The mild heating necessary for coacervation process did not affect the chemical stability of peptides, since no relevant amount of A21-desamido insulin, the main thermal degradation product of insulin, was detected after encapsulation in nanoparticles. SLN can work as a sustained release system in vitro for peptides (i.e., leuprolide), because of the entrapment of ion pair within the lipid matrix.

\section{Acknowledgment}

The support of the Italian Minister of Research (MIUR) under PRIN 06 Program is gratefully acknowledged.

\section{References}

[1] R. H. Müller and S. A. Runge, "Solid lipid nanoparticles (SLN $\left.{ }^{\circledR}\right)$ for controlled drug delivery," in Submicron Emulsions in Drug Targeting and Delivery, S. Benita, Ed., pp. 219-234, Harwood Academic Publishers, Amsterdam, The Netherlands, 1998.

[2] A. J. Almeida and E. Souto, "Solid lipid nanoparticles as a drug delivery system for peptides and proteins," Advanced Drug Delivery Reviews, vol. 59, no. 6, pp. 478-490, 2007.

[3] R. H. Müller, K. Mäder, and S. Gohla, "Solid lipid nanoparticles (SLN) for controlled drug delivery-a review of the state of the art," European Journal of Pharmaceutics and Biopharmaceutics, vol. 50, no. 1, pp. 161-177, 2000.

[4] H. Reithmeier, J. Herrmann, and A. Göpferich, "Lipid microparticles as a parenteral controlled release device for peptides," Journal of Controlled Release, vol. 73, no. 2-3, pp. 339-350, 2001.

[5] M. García-Fuentes, D. Torres, and M. J. Alonso, "Design of lipid nanoparticles for the oral delivery of hydrophilic macromolecules," Colloids and Surfaces B, vol. 27, no. 3, pp. 159-168, 2002.

[6] M. Gallarate, M. Trotta, L. Battaglia, and D. Chirio, "Preparation of solid lipid nanoparticles from W/O/W emulsions: preliminary studies on insulin encapsulation," Journal of Microencapsulation, vol. 26, no. 5, pp. 394-402, 2009.

[7] Y. M. Kwon, M. Baudys, K. Knutson, and S. W. Kim, "In situ study of insulin aggregation induced by water-organic solvent interface," Pharmaceutical Research, vol. 18, no. 12, pp. 17541759, 2001.

[8] L. Battaglia, M. Trotta, M. Gallarate, M. E. Carlotti, G. P. Zara, and A. Bargoni, "Solvent lipid nanoparticles formed by solvent-in-water emulsion diffusion technique: development and influence of insulin stability," Journal of Microencapsulation, vol. 14, pp. 672-684, 2007.

[9] J. D. Meyer and M. C. Manning, "Hydrophobic ion pairing: altering the solubility properties of biomolecules," Pharmaceutical Research, vol. 15, no. 2, pp. 188-193, 1998.

[10] D. Quintanar-Guerrero, E. Allémann, H. Fessi, and E. Doelker, "Applications of the ion-pair concept to hydrophilic substances with special emphasis on peptides," Pharmaceutical Research, vol. 14, no. 2, pp. 119-127, 1997.

[11] M. E. Powers, J. Matsuura, J. Brassell, M. C. Manning, and E. Shefter, "Enhanced solubility of proteins and peptides in nonpolar solvents through hydrophobic ion pairing," Biopolymers, vol. 33, no. 6, pp. 927-932, 1993. 
[12] L. Battaglia, M. Gallarate, R. Cavalli, and M. Trotta, "Solid lipid nanoparticles produced through a coacervation method," Journal of Microencapsulation, vol. 27, no. 1, pp. 78-85, 2010.

[13] M. A. Bianco, M. Gallarate, M. Trotta, and L. Battaglia, "Amphotericin B loaded SLN prepared with the coacervation technique," Journal of Drug Delivery Science and Technology, vol. 20, no. 3, pp. 187-191, 2010.

[14] M. Gallarate, M. Trotta, L. Battaglia, and D. Chirio, "Cisplatin loaded SLN produced by coacervation technique," Journal of Drug Delivery Science and Technology, vol. 20, no. 5, pp. 343$347,2010$.

[15] M. E. Powers, J. Matsuura, J. Brassell, M. C. Manning, and E. Shefter, "Enhanced solubility of proteins and peptides in nonpolar solvents through hydrophobic ion pairing," Biopolymers, vol. 33, no. 6, pp. 927-932, 1993.

[16] A. Adjei, S. Rao, J. Garren, G. Menon, and M. Vadnere, "Effect of ion-pairing on 1-octanol-water partitioning of peptide drugs. I: the nonapeptide leuprolide acetate," International Journal of Pharmaceutics, vol. 90, no. 2, pp. 141-149, 1993.

[17] J. Brange, Stability of Insulin, Kluwer Academic Publishers, Boston, Mass, USA, 1994.

[18] J. Brange, Galenics of Insulin, Springer, Berlin, Germany, 1987.

[19] G. Khaksa, K. Nalini, M. Bhat, and N. Udupa, "Highperformance liquid chromatographic determination of insulin in rat and human plasma," Analytical Biochemistry, vol. 260, no. 1, pp. 92-95, 1998.

[20] V. Jenning, M. Schäfer-Korting, and S. Gohla, "Vitamin Aloaded solid lipid nanoparticles for topical use: drug release properties," Journal of Controlled Release, vol. 66, no. 2-3, pp. 115-126, 2000.

[21] M. E. Carlotti, E. Ugazio, S. Sapino, E. Peira, L. Battaglia, and R. Cavalli, "Photodegradation of caffeic acid in W/O/W emulsions in the absence and in the presence of $\mathrm{TiO}_{2}$," Journal of Dispersion Science and Technology, vol. 29, no. 10, pp. 1435$1444,2008$.

[22] J. Seidenfeld, D. J. Samson, V. Hasselblad et al., "Single-therapy androgen suppression in men with advanced prostate cancer: a systematic review and meta-analysis," Annals of Internal Medicine, vol. 132, no. 7, pp. 566-577, 2000.

[23] K. Westesen, H. Bunjes, and M. H. J. Koch, "Physicochemical characterization of lipid nanoparticles and evaluation of their drug loading capacity and sustained release potential," Journal of Controlled Release, vol. 48, no. 2-3, pp. 223-236, 1997. 

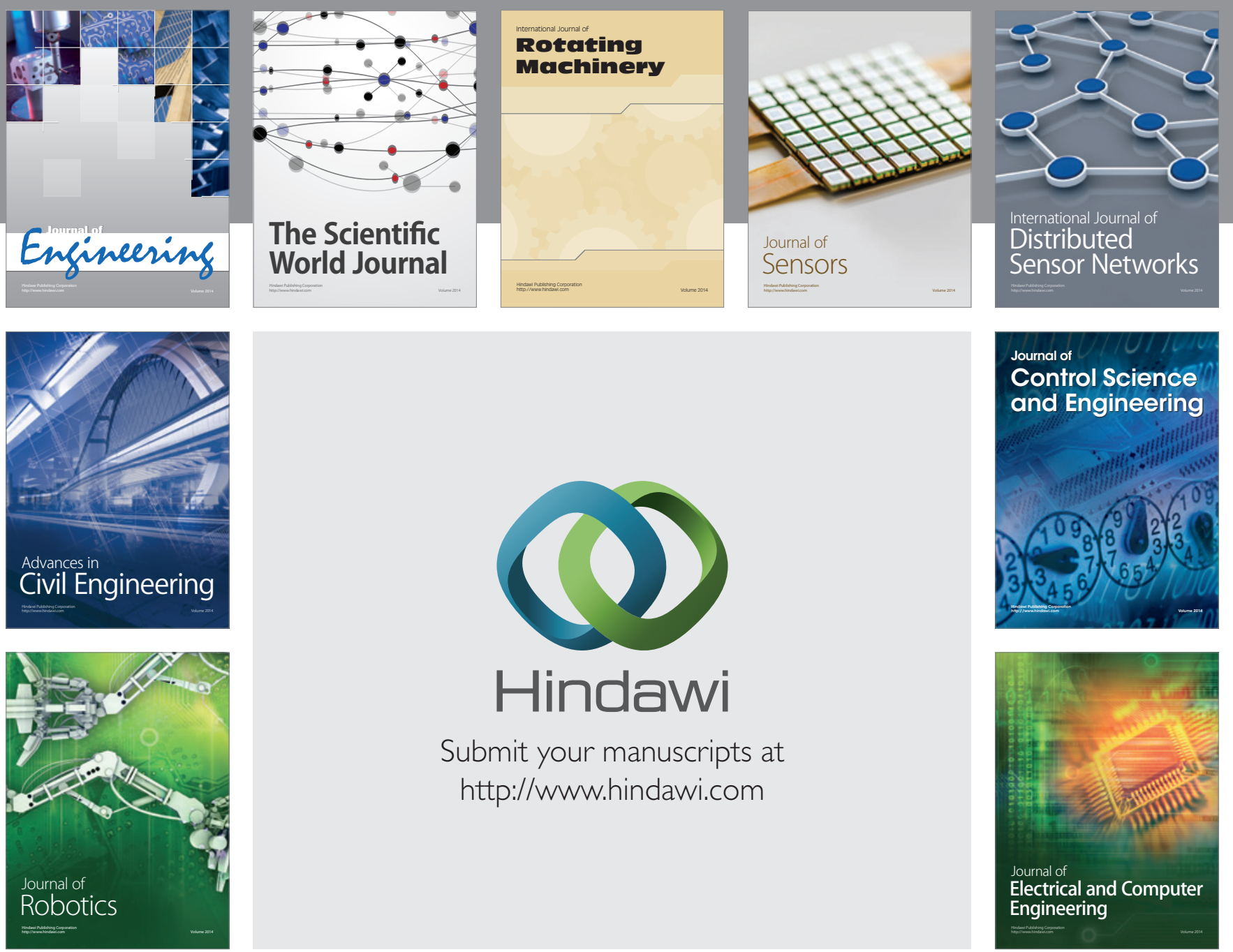

Submit your manuscripts at

http://www.hindawi.com
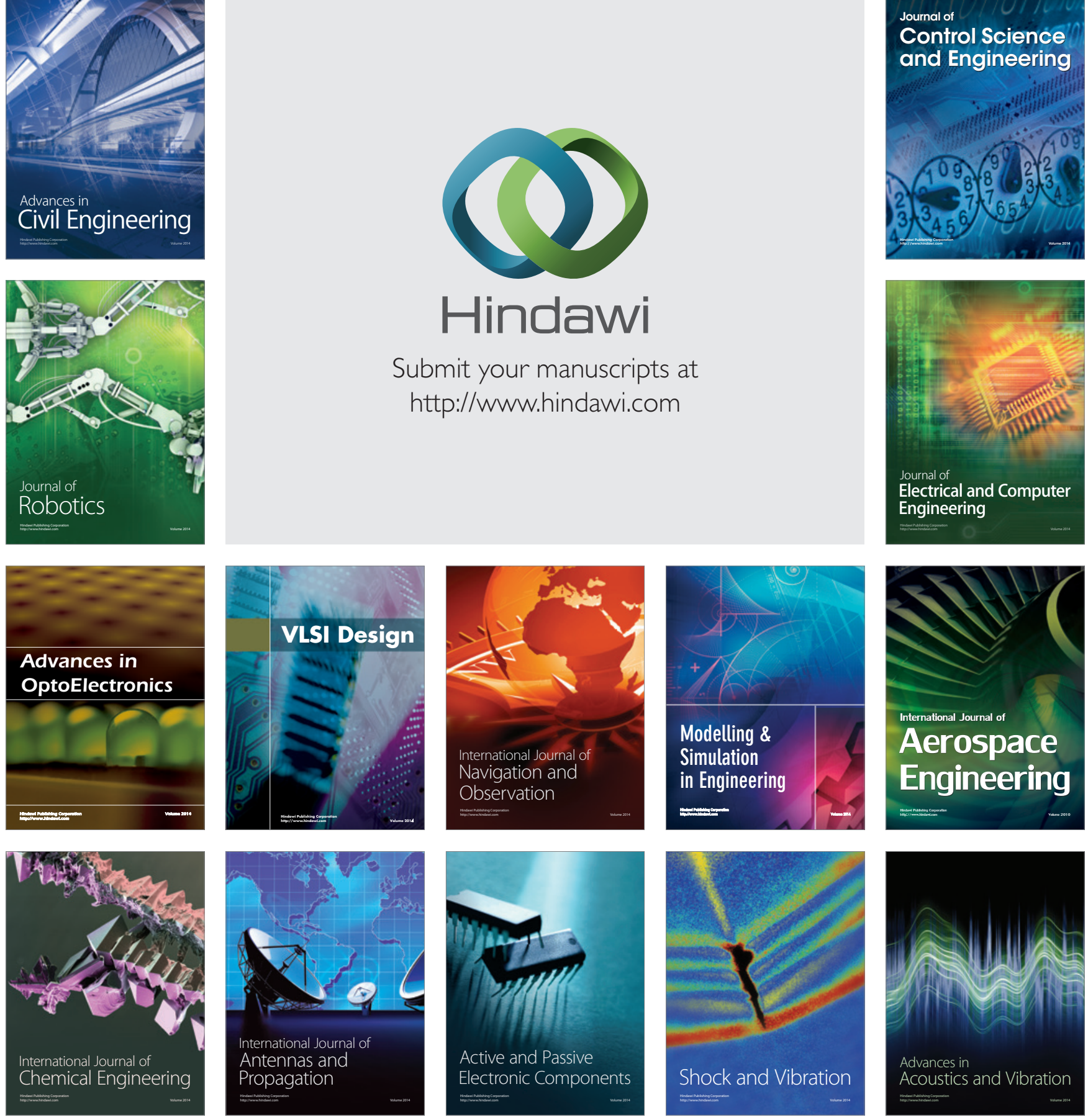